\section{3-D PLOT, a FORTRAN IV program for projecting a triplex of factor loadings}

KENN FINSTUEN

Our Lady of the Lake University, San Antonio, Texas 78285

and

\section{DENNIS WENZEL}

St. Mary's University of Texas, San Antonio, Texas 78284

Description. This program plots the projected factor loadings from a factor analysis or multidimensional scaling output in three dimensions. A triplex is formed when the output series of two two-dimensional joined graphs is folded $90 \mathrm{deg}$ along their common side. The resulting orthogonally opposed three dimensions project a rectangular coordinate system known as a left-handed system (Wade \& Taylor, 1969, pp. 257-264) in threespace. With a 31-point scale along each axis, the euclidian space generated results in $29,791\left(31^{3}\right)$ possible plot points. Grid marks and factor loading scales are indicated for each of the labeled axes.

Input. The program is interactive and provides instructions and rationale upon request. The study title is also entered. Items or variables are coded as alpha characters. The positive and negative loadings for each item are entered to three decimal places for the $\mathrm{X}, \mathrm{Y}$, and $\mathrm{Z}$ factor dimensions.

Output. The output consists of two 31-point scaled, two-dimensional plotted graphs, and a data summary table listing the coded variable character and loadings on the three dimensions. The first, or top, graph delimits the $\mathrm{XZ}$ plane, the second, or bottom, graph delimits the $X Y$ plane. Variables are plotted as alpha-character projections on both graphs of the triplex. In the event that two or more variables occupy the same point on either graph, an ampersand (\&) is displayed.

Limitations. Up to 99 variables or items may be entered. Axes of the dimensions are assumed to be orthogonal. There may not be any missing data. If more than three dimensions ( $\mathrm{n}$ ) are to be compared $(n>3)$, the fourth term of the binomial expansion $n(n-1)(n-2) / 6$ (McNemar, 1969, pp. 43-44) may be used to arrive at the number of triplices needed. Dimension loadings may then be recoded as $\mathrm{X}, \mathrm{Y}$, or $Z$. The program was written using $25 \mathrm{~K}$ core.

Running Time. Full run time for computations and graphic printout on a Honeywell Series 600/6000 equipped with SF 6690 teletypewriter terminal has been less than $10 \mathrm{~min}$.

Availability. A program list and write-up may be obtained free from Kenn Finstuen, Psychology Department, Our Lady of the Lake University, San Antonio, Texas 78285 .

\section{REFERENCES}

McNemar, Q. Psychological statistics (4th ed.). New York: Wiley, 1969.

WADE, T., \& TAYLOR, H. Contemporary analytic geometry. New York: McGraw-Hill, 1969. 